OPEN ACCESS

Edited by: Walter Adriani Istituto Superiore di Sanità (ISS), Italy

Reviewed by:

Elodie Ey,

Institut Pasteur, France

Yuri Bozzi,

University of Trento, Italy

*Correspondence:

Céline Plachez

cplachez@hussmanautism.org

Shiyong Huang

shuang@hussmanautism.org

Received: 27 July 2018 Accepted: 15 October 2018 Published: 13 November 2018

Citation:

Park SM, Plachez $C$ and Huang S (2018) Sex-Dependent Motor Deficit and Increased Anxiety-Like States in

Mice Lacking Autism-Associated

Gene Slit3.

Front. Behav. Neurosci. 12:261. doi: 10.3389/fnbeh.2018.00261

\section{Sex-Dependent Motor Deficit and Increased Anxiety-Like States in Mice Lacking Autism-Associated Gene Slit3}

\author{
Su Mi Park ${ }^{1}$, Céline Plachez ${ }^{2 \star}$ and Shiyong Huang ${ }^{1 *}$ \\ ${ }^{1}$ Laboratory of Neural Circuits \& Behavior, Program in Neuroscience, Hussman Institute for Autism, Baltimore, MD, \\ United States, ${ }^{2}$ Autism \& Brain Development Laboratory, Program in Neuroscience, Hussman Institute for Autism, Baltimore, \\ $M D$, United States
}

Altered neuronal connectivity has been implicated in the pathophysiology of Autism Spectrum Disorder (ASD). SLIT/ROBO signaling plays an important role in developmental processes of neuronal connectivity, including axon guidance, neuronal migration, and axonal and dendritic branching. Genetic evidence supports that SLIT3, one of the genes encoding SLITs, is associated with ASD. Yet the causal link between SLIT3 mutation and autism symptoms has not been examined. Here we assessed ASD-associated behaviors in Slit3 knockout (KO) mice. Our data showed that Slit3-KO mice exhibited reduced marble burying behaviors but normal social behaviors. In addition, Slit3-KO mice displayed hypolocomotion in the open field test and impaired motor coordination in the rotarod test. Anxiety-like behaviors were mainly observed in female KO mice assessed by three types of behavioral tests, namely, the open field test, elevated plus maze test, and light/dark box test. No differences were observed between $\mathrm{KO}$ and wildtype mice in recognition memory in the novel object recognition test or depression-like behavior in the tail suspension test. Taken together, loss of Slit3 may result in disrupted neural circuits related to motor function and increased anxiety-like states, which are co-occurring symptoms in ASD.

Keywords: autism(ASD), Slit3, anxiety, hypolocomotion, motor coordination

\section{INTRODUCTION}

SLITs, encoded by the genes Slit1-3, are chemorepellents that bind to Roundabout (ROBO) receptors to guide axons to find correct pathways during brain development (Brose et al., 1999; Nguyen-Ba-Charvet and Chédotal, 2002; Long et al., 2004). SLIT/ROBO signaling plays an important role in neuronal migration, cell proliferation, and axonal and dendritic branching, which are required for the normal development of neuronal connectivity (Hu, 1999; Wang et al., 1999; Shu and Richards, 2001; Whitford et al., 2002; Miyashita et al., 2004; Plachez and Richards, 2005; Andrews et al., 2007; Plachez et al., 2008; Borrell et al., 2012). For instance, the formation of thalamocortical, corticofugal, and callosal connections partially or completely depends on SLIT family (Bagri et al., 2002; Unni et al., 2012) and ROBO1/2 receptors (Lopez-Bendito et al., 2007). Altered neuronal connectivity is a potential neural signature of Autism Spectrum Disorder (ASD) (Menon, 2013; Mohammad-Rezazadeh et al., 2016). Studies using functional magnetic resonance imaging (fMRI), electroencephalography (EEG), or magnetoencephalography (MEG) found 
hyperconnectivity and hypoconnectivity in brains of ASD patients (Lynch et al., 2013; Di Martino et al., 2014; O’Reilly et al., 2017). Along with altered functional connectivity, brain structural abnormalities were also discovered in ASD (Freitag et al., 2009; Hardan et al., 2009; Oblak et al., 2011; Uddin et al., 2011). These lines of evidence suggest that functional changes in the SLIT/ROBO pathway may hinder the normal development of neural connectivity, resulting in neurodevelopmental conditions such as ASD.

Indeed, aberrant SLIT/ROBO signaling has been implicated in the pathogenesis of ASD (Anitha et al., 2008; Blockus and Chédotal, 2014; Perez et al., 2016). It has been shown that mRNA and protein expression of $\mathrm{ROBO} 2$, is reduced in the anterior cingulate cortex of ASD postmortem brains (Suda et al., 2011). In addition, $R O B O 1$ gene expression is downregulated in lymphoblastoid cell lines derived from children with autism (Hu et al., 2006). Gene variations of $R O B O 3 / 4$ and increased expression of SLIT1 are also associated with autism (Anitha et al., 2008; Bakos et al., 2015).

Importantly, SLIT3 is suggested as an autism-risk gene by several genetic studies. The primary evidence is from a wholeexome sequencing study in which single nucleotide variance of SLIT3 was identified in two multiplex ASD families (Cukier et al., 2014). Single nucleotide variance of SLIT3 was also reported in the simplex ASD family from analyses using the Simons Simplex Collection data set (Krupp et al., 2017). Additionally, the chromosomal abnormality of $5 \mathrm{q} 35$, where SLIT3 is located, is linked to neurodevelopmental disorders (Schafer et al., 2001; Schiffer et al., 2003; Bækvad-Hansen et al., 2006; Menten et al., 2006). In line with this notion, it has been reported that SLIT3 mutations are associated with schizophrenia (Shi et al., 2004) and major depressive disorder (Glessner et al., 2010), which may be attributed to the overlapped genetic susceptibility between ASD and other neuropsychiatric disorders (Carroll and Owen, 2009; Cukier et al., 2014; McCarthy et al., 2014; Khanzada et al., 2017). However, despite these indications, no study to date has examined whether mutations of SLIT3 leads to ASD-related symptoms.

In this study, several ASD-associated behaviors in Slit3-KO mice were examined, including motor behaviors (open field test and rotarod test), anxiety-like behaviors (light/dark box and elevated plus maze test), depression-like behaviors (tail suspension test), cognitive ability (novel object recognition test), social behaviors (three chamber test), and repetitive behaviors (marble burying test). Behavioral assessments in Slit3-KO mice revealed that the absence of Slit3 resulted in increased anxietylike behaviors and altered motor behaviors. Since behavioral criteria are relevant to the diagnosis of ASD, Slit3-KO mice with


FIGURE 1 | Slit3-KO mice showed normal social behavior in the three-chamber social test. (A) Both WT and KO mice spent longer time around the cup with a novel mouse than the cup with an object. WT: ${ }^{*} p<0.001, \mathrm{KO}:{ }^{*} p<0.001, t$-test. (B) No significant difference in preference index for social stimulus between WT and KO mice. n.s., $p=0.167$, $t$-test. (C) Mice spent longer time around the cup with a novel mouse than with a familiar mouse regardless of their genotypes. WT: ${ }^{\star} p=0.012$, $\mathrm{KO}:{ }^{\star} p=0.003$, $t$-test. (D) No significant difference in preference index for social novelty between WT and KO mice. n.s.: $p=0.619, t$-test. The preference index was calculated as Equation 1. The data in the bar chart are presented as mean \pm SEM. Sample size is indicated in parentheses. 
behavioral characterization may be a useful animal model for the study of clinical interventions in autism.

\section{RESULTS}

\subsection{Normal Social Approach and Preference Behaviors in Slit3-KO Mice}

In order to examine whether the deletion of Slit3 results in any deficit of social behaviors, social approach and preference behaviors in Slit3-KO mice were assessed using the threechamber social test. As shown in Figure 1, Slit3-KO mice spent more time around a cup with a novel mouse than an object displayed $\left[t_{(16)}=4.84, p<0.001, t\right.$-test $]$, which was comparable to the WT mice $\left[t_{(16)}=4.86, p<0.001, t\right.$-test; Figure 1A]. The preference index to social stimulus was not significantly different between WT and Slit3-KO mice $\left[t_{(32)}=1.42, p=0.167\right.$, $t$-test; Figure 1B], suggesting normal social approach behavior in Slit3KO mice. Similarly, when each sex group was analyzed separately, there was no significant genotype effect in the preference index for social stimulus [Female: $t_{(16)}=1.58, p=0.134$; Male: $t_{(14)}=0.40, p=0.693$; $t$-test $]$. They also exhibited normal social preference behavior as they spent more time around a cup with a novel mouse than with a familiar mouse $\left[t_{(16)}=3.51\right.$, $p=0.003, t$-test $]$, which was comparable to WT controls $\left[t_{(16)}\right.$ $=2.85, p=0.012$; Figure 1C], without any significant difference in preference to social novelty $\left[t_{(32)}=0.50, p=0.619, t\right.$-test; Figure 1D]. Similarly, when each sex was analyzed separately, there was no significant genotype effect in the preference index for social novelty [Female: $t_{(16)}=0.19, p=0.428$; Male: $t_{(14)}=$ $0.75, p=0.620 ; t$-test $]$.

\subsection{Suppressed Repetitive Behavior, Hypolocomotion, and Impaired Motor Coordination in Slit3-KO Mice}

Repetitive behaviors in Slit3-KO mice were examined by assessing animals' marble burying behavior. Our results showed that Slit3-KO mice buried significantly fewer marbles than WT mice $(U=106.5, p=0.002$, Mann-Whitney test; Figures 2A,B). When each sex group was analyzed separately, both female and male Slit3-KO mice buried fewer marbles than the WT controls (Female: $U=24, p=0.041$, Mann-Whitney test; Male: $U=17.5$, $p=0.011$, Mann-Whitney test; Figures 2C,D).

General locomotive behaviors in Slit3-KO mice were assessed using 30-min open field tests. Slit3-KO mice traveled significantly shorter distances than WT mice $\left[t_{(59)}=3.50, p<0.001\right.$, $t$-test; Figure 3A]. When each sex group was analyzed separately, the difference was mainly driven by male $\mathrm{KO}$ mice [Male: $t_{(32)}=3.64$, $p<0.001$, $t$-test; Female: $t_{(25)}=1.03, p=0.312$, $t$-test; Figure 3B]. Similarly, when the travel distance was binned every 5 min, male $\mathrm{KO}$ mice consistently traveled less distance during the 30 -min testing period $\left[F_{(1,32)}=13, p=0.001\right.$, genotype effect, two-way rmANOVA; Figure $3 \mathrm{C}$ ]. The male WT and male $\mathrm{KO}$ mice traveled less distance as time passed, illustrating similar levels of habituation to the novel environment $\left[F_{(5,160)}=37.6\right.$, $p<0.001$, time effect, two-way rmANOVA; Figure 3C]. In female mice, $\mathrm{KO}$ mice tended to travel less distance than WT
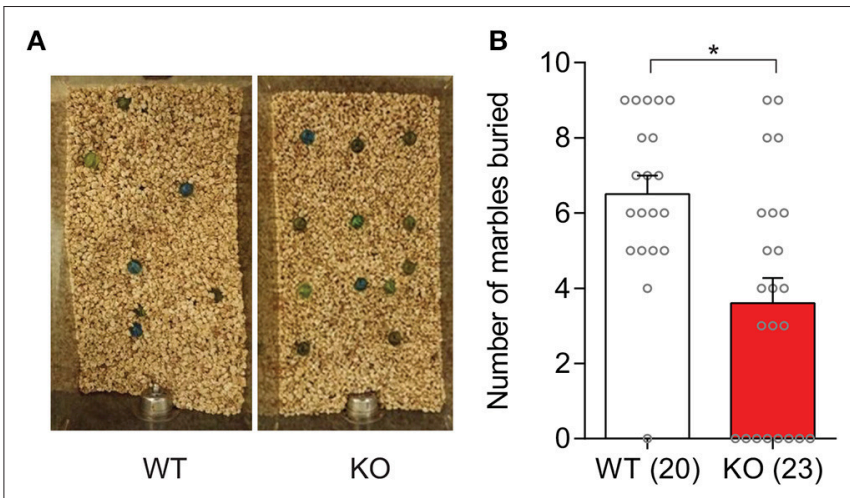

C

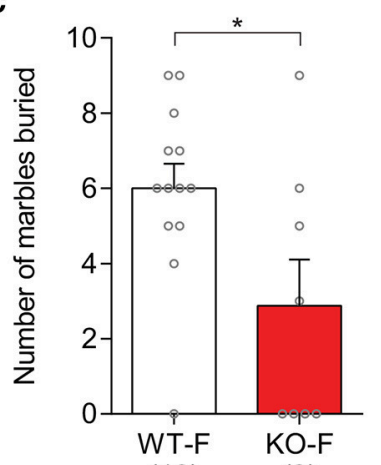

(13)

(8)

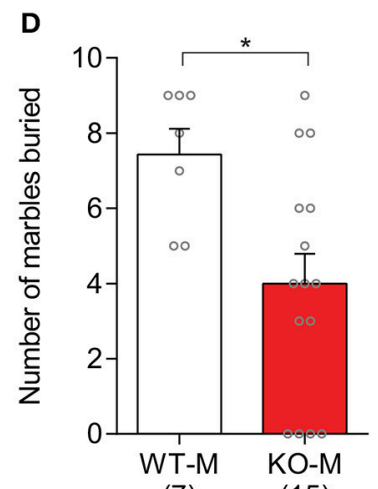

(7)

(15)

FIGURE 2 | Slit3-KO mice showed suppressed marble burying behavior. (A) Example image of marbles buried by WT and KO mice. (B) KO mice buried significantly fewer marbles compared to WT mice. ${ }^{*} p=0.002$, Mann-Whitney test. (C) Number of marbles that female mice buried in each genotype.

${ }^{*} p=0.041$, Mann-Whitney test. (D) Number of marbles that male mice buried in each genotype. ${ }^{*} p=0.011$, Mann-Whitney test. The data in the bar chart are presented as mean \pm SEM. Sample size is indicated in parentheses. F, female; M, male.

mice during the first 5 min of the test, but it was not statistically significant $\left[t_{(25)}=1.88, p=0.072\right.$, $t$-test; Figure 3D .

Motor coordination in Slit3-KO mice was assessed during three trials of the accelerating rotarod test for 2 consecutive days. Slit3-KO mice showed impaired rotarod performance, as the latency to fall off the rod was shorter than WT mice over six trials in the accelerating rotarod test, indicating impaired motor coordination in Slit3-KO mice $\left[F_{(1,40)}=6.63, p=0.014\right.$, genotype effect, two-way rmANOVA; Figure 4A]. However, as trials were repeated, both the WT and $\mathrm{KO}$ mice remained on the rod for longer periods of time, suggesting normal learning rate in the KO mice $\left[F_{(5,200)}=35.4, p<0.001\right.$, trial effect, twoway rmANOVA; Figure 4A]. When each sex group was analyzed separately, only female $\mathrm{KO}$ mice showed impaired rotarod performance compared to female WT mice $\left[F_{(1,21)}=5.99\right.$, $p=0.023$, genotype effect, two-way rmANOVA; Figure 4B], while the performance of the male $\mathrm{KO}$ mice was not significantly different from WT controls $\left[F_{(1,17)}=0.53, p=0.477\right.$, genotype effect, two-way rmANOVA; Figure 4C]. However, both male and female mice displayed longer latency to fall off the rod in the 


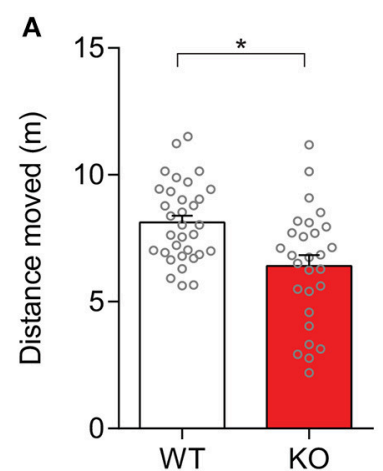

(33)

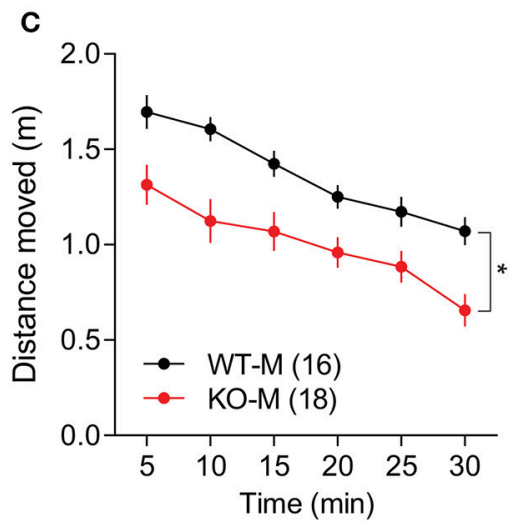

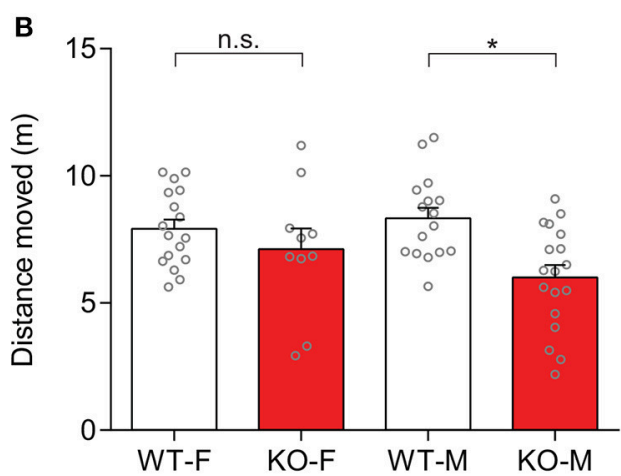

(17)

(10)

(16)

(18)

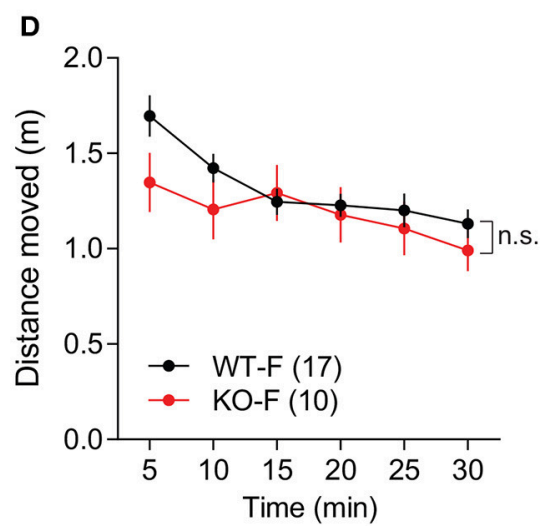

FIGURE 3 | Slit3-KO mice were hypolocomotive in the open field test. (A) KO mice traveled a shorter distance than WT mice during a 30-min open field test. ${ }^{\star} p<0.001$, $t$-test. (B) When each sex group was analyzed separately, only male KO mice showed hypolocomotion compared to male WT mice. Male: ${ }^{*} p<0.001$, Female: n.s.: $p=0.312$, $t$-test. (C) Distance that male WT and KO mice traveled in 5-min time bin. * $p=0.001$, genotype effect, two-way rmANOVA. (D) Distance that female WT and KO mice traveled in 5-min time bin. n.s.: $p=0.312$, genotype effect, two-way rmANOVA. The data in the bar chart are presented as mean \pm SEM. Sample size is indicated in parentheses. F, female; M, male.

later trials regardless of the genotype, indicating normal learning rate in the $\mathrm{KO}$ mice [Male: $F_{(5,85)}=9.30, p<0.001$; Female: $F_{(5,105)}=29.5, p<0.001$; trial effect, two-way rmANOVA; Figures 4B,C]. Although the performance of male KO mice over the trials was similar to WT mice in the rmANOVA analysis, the latency to fall off the rod in the first trial was significantly shorter than controls, suggesting impaired motor coordination in the $\mathrm{KO}$ mice $\left[t_{(17)}=3.01, p=0.008, t\right.$-test; Figure 4C].

\subsection{Increased Anxiety-Like Behaviors in Slit3-KO Mice}

In order to assess anxiety-like behaviors in Slit3-KO mice, explorative behavior in the center of the arena during the first 10 min of the open field test was analyzed. There was no significant genotype difference in the duration of time that animals spent in the center arena $\left[t_{(59)}=0.51, p=0.614, t\right.$-test; Figure 5A $]$. When each sex group was analyzed separately, female KO mice spent significantly less time in the center arena than female WT mice, indicating increased anxiety-like states in the female $\mathrm{KO}$ mice $\left[t_{(25)}=2.16, p=0.041, t\right.$-test; Figures 5B,C]. The duration that male $\mathrm{KO}$ mice spent in the center arena was not significantly different from the male WT mice $\left[t_{(32)}=0.84, p=0.409\right.$, $t$ test; Figures 5B,C]. The distance that the animals traveled during the first 10 min of the test within each sex group was also analyzed to examine the influence of possible hypolocomotion on the strong thigmotaxis shown only in female KO mice. The distance that female $\mathrm{KO}$ mice traveled was not significantly different from female WT mice, although there was a tendency of hypolocomotion $\left[t_{(25)}=1.79, p=0.085\right.$, $t$-test; Figure 5D], suggesting a heightened anxiety-like state but a normal activity level in female Slit3-KO mice.

Anxiety-like behaviors in Slit3-KO mice were further assessed by measuring the duration that animals spent in the open arm of the elevated plus maze (Silverman et al., 2010). The Slit3-KO mice spent reduced percentage of time in the open arm of the maze compared to WT mice ( $U=338, p=0.007$, Mann-Whitney test; Figure 6A), indicating heightened anxiety-like states in the KO mice. When each sex group was analyzed separately, female KO mice spent less percentage of time in the open arm of the maze than female WT mice, while male KO mice spent comparable time in the open arm to the controls (Female: $U=115, p=0.023$; Male: $U=61, p=0.233$; Mann-Whitney test; Figures 6B-D), suggesting increased anxiety-like states only in the female $\mathrm{KO}$ mice as seen in the open field tests (Figure 5).

The observed anxiety-like behaviors in Slit3-KO mice were further assessed based on the number of transitions that animals 
made between light and dark compartments. The Slit3-KO mice displayed increased anxiety-like behaviors as they made significantly fewer transitions between both chambers than WT mice $\left[t_{(64)}=4.57, p<0.001, t\right.$-test; Figure 7A]. When each sex group was analyzed separately, both male and female $\mathrm{KO}$ mice made significantly fewer transitions to the light compartment compared to the relative controls [Female: $t_{(37)}=3.26, p=0.002$; Male: $t_{(25)}=3.16, p=0.004 ; t$-test; Figures 7B,C].

\subsection{Normal Object Recognition Memory and No-Depression-Like Behaviors in Slit3 KO Mice}

The hippocampal dependent memory in Slit3-KO mice was assessed in the novel object recognition test. Slit3-KO mice were able to discriminate between a familiar object that they had explored during the training session $10 \mathrm{~min}$ prior to the test session and a novel object. Based on the discrimination index, there was not a significant difference between $\mathrm{KO}$ and WT mice $\left[t_{(53)}=0.96, p=0.340, t\right.$-test; Figure 8A]. The analysis within each sex group did not find any genotype effect [Female: $t_{(23)}=0.34, p=0.405$; Male: $t_{(28)}=1.05, p=0.578$; t-test].

The depression-like behaviors in Slit3-KO mice were assessed in the tail suspension test. The elicited immobility duration in KO mice was not significantly different from that in WT controls $\left[t_{(38)}=0.03, p=0.972, t\right.$-test; Figure $\left.8 \mathbf{B}\right]$, suggesting that there is no apparent depression-like trait in the Slit3-KO mice. The analysis within each sex group did not find any genotype effect [Female: $t_{(28)}=0.16, p=0.706$; Male: $t_{(8)}=0.10, p=0.605$; t-test].

\section{DISCUSSION}

This study provides novel insight into behavioral phenotypes of the mouse model with the deletion of Slit3. Our findings showed that Slit3-KO mice exhibited increased anxiety-like behaviors and altered motor behaviors, but normal social approach and preference behaviors. Phenotyping Slit3-KO mice in ASDassociated behaviors deepens the understanding of how SLIT3 mutations may affect ASD symptoms.

Aberrant motor behaviors are the distinct phenotype in Slit3-KO mice supported by hypolocomotion in the open field test and impaired motor coordination in the accelerating rotarod task. Although aberrant motor behavior is not the core behavioral criterion of ASD, the impairment in motor function is a symptom strongly associated with ASD (Jeste, 2011; Abu-Dahab et al., 2013). Slit3 mRNA is expressed in the motor column of spinal cord and cranial motor nuclei during embryonic and postnatal periods, and in the cerebellum and basal ganglia during postnatal periods of rodents (Yuan et al., 1999; Marillat et al., 2002), which supports the significant role that Slit3 plays in the development and maintenance of neuronal connectivity for motor functions. In addition, the association of single nucleotide polymorphism of SLIT3 with Parkinson's disease, a disorder mainly focused on motor functions, further supports the importance of SLIT3 for the maintenance of motor
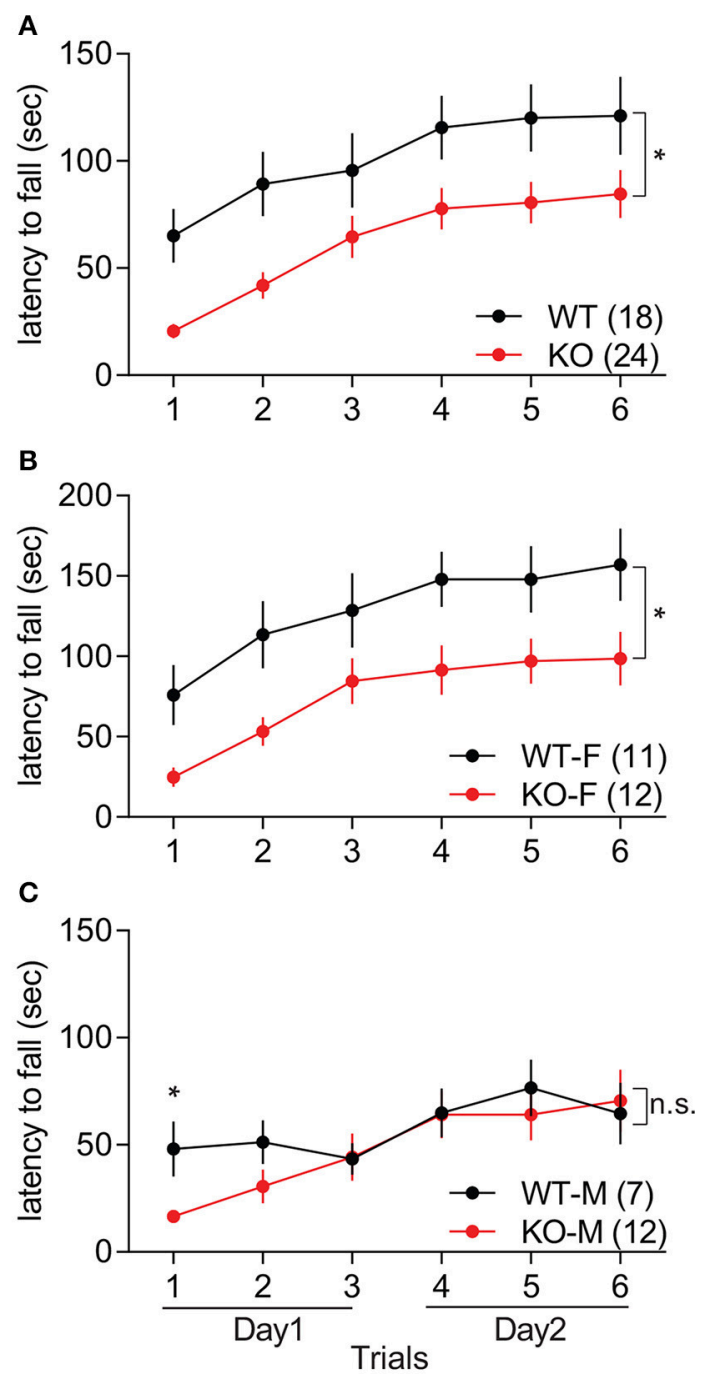

FIGURE 4 | Slit3-KO mice displayed impaired motor coordination in the accelerating rotarod test. (A) KO mice showed shorter latency to fall off the rotarod than WT mice. ${ }^{*} p=0.014$, genotype effect, two-way rmANOVA. (B) Latency to fall off the rotarod in female mice. ${ }^{*} p=0.023$, genotype effect, two-way rmANOVA. (C) Latency to fall off the rotarod in male mice. n.s.: $p=0.477$, genotype effect, two-way rmANOVA. ${ }^{*} p=0.008, t$-test at the 1 st trial. The data are presented as mean \pm SEM. Sample size is indicated in parentheses. F, female; M, male.

pathways (Lin et al., 2009). Thus, deletion of SLIT3 may result in aberrant development/maintenance of motor functions and lead to impaired motor coordination or reduced locomotive behaviors in autism.

A high prevalence of anxiety has been found in individuals with ASD and often impacts the quality of daily life (White et al., 2009; van Steensel et al., 2011; Kerns et al., 2014). Female Slit3-KO mice displayed stronger thigmotaxis during the first 10 min of the open field test, which indicates that they were more anxious. The increased anxiety-like state in Slit3-KO mice was further supported by anxiety-like behaviors observed in the elevated plus maze test and the light/dark box test. Slit3 mRNA 
A

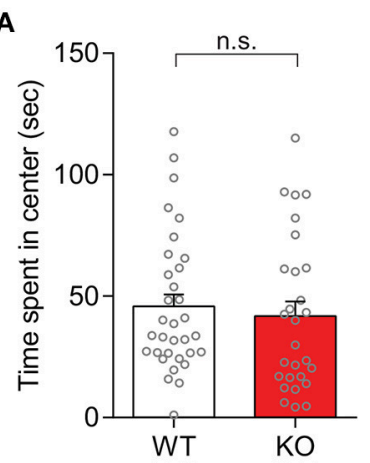

(33)

B

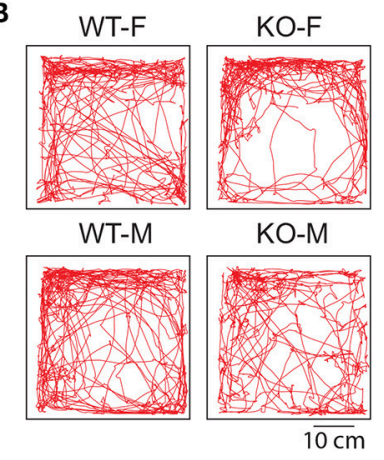

C

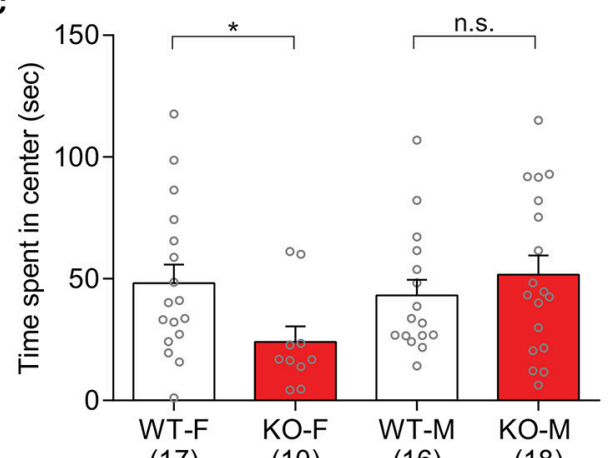

(17)

(10)

(16)

(18)

D

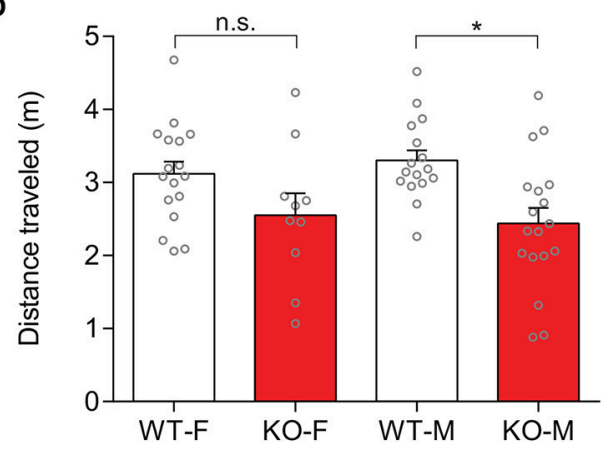

FIGURE 5 | Slit3-KO mice displayed anxiety-like behaviors during the first 10 mins of the open field test. (A) Duration that each genotype group spent in the center arena of the open field. n.s.: $p=0.614$, $t$-test. (B) Representative maps illustrated mice's track in the open field during the first 10 min of the test. (C) Female KO mice spent less time in the center arena of the open field compared to female WT mice. Female: ${ }^{*} p=0.041$, Male: n.s.: $p=0.409, t$-test. (D) Distance that animals traveled during the first 10 min of the test. Female: n.s.: $p=0.085$, Male: ${ }^{*} p=0.002, t$-test. The data in the bar chart are presented as mean \pm SEM. Sample size is indicated in parentheses. F, female; M, male.

was also detected in the hippocampus, amygdala, and bed nucleus of the stria terminalis of rats during embryonic and postnatal periods (Marillat et al., 2002). As these brain areas are known to be involved in the regulation of anxiety (Calhoon and Tye, 2015; Tovote et al., 2015), the observed expression pattern implicates that Slit3 may be critical to the development and regulation of neuronal circuits for anxiety. In addition, our results showed that there were sex differences in some behavioral tests. For example, female Slit3-KO mice displayed anxiety-like behaviors in the elevated plus maze test and open field test while male KO mice did not. This suggests that the deletion of Slit3 may influence animal behaviors in a sex-dependent manner, which is supported by evidence that the expression of Slit3 is sex biased (Hou et al., 2017) and regulated by the female sex hormone, estrogen (Greaves et al., 2014). Moreover, it was reported that, depending on the types of behavioral tests used, mouse strain and gender have different impacts on anxiety measures (Griebel et al., 2000; Võikar et al., 2001; An et al., 2011), which may explain the results that male Slit3-KO mice exhibited increased anxiety-like behaviors only in the light/dark box test but not in the other two tests.

In marble burying tests used as a measure of repetitive behaviors, one of the diagnostic criteria for ASD, Slit3-KO mice displayed suppressed marble burying behavior. Notably, several other autism-related models also displayed decreased marble burying behaviors despite their increased repetitive behaviors. For example, Ephrin-A KO mice (Wurzman et al., 2015), Shank3KO mice (Kouser et al., 2013), and a mouse model of $15 q$ duplication syndrome (Tamada et al., 2010) showed reduced marble burying behaviors. It is possible that reduced marble burying behaviors in Slit3-KO mice may reflect the aberrant motor behaviors, which were observed in both the open field test and rotarod test, rather than measuring an alteration in the tendency toward repetitive behavior itself.

Despite the high level of Slit3 expression in the hippocampus, deletion of the Slit3 gene did not change object recognition memory in KO mice. It is possible that the presence of SLIT3 in the hippocampus may be involved in anxiety regulation but not memory, as previous studies show that the dorsal and ventral hippocampus regulate memory and anxiety respectively (Fanselow and Dong, 2010). Deletion of Slit3 may also influence other hippocampal-related cognitive functions such as spatial memory or long-term recognition memory rather than the object recognition memory tested here. Previous studies have found functional changes in SLIT3 genes to be associated with depression. For example, duplications of the SLIT3 locus were observed in major depressive disorder cases (Glessner et al., 2010), and families carrying an alteration in SLIT3 presented 


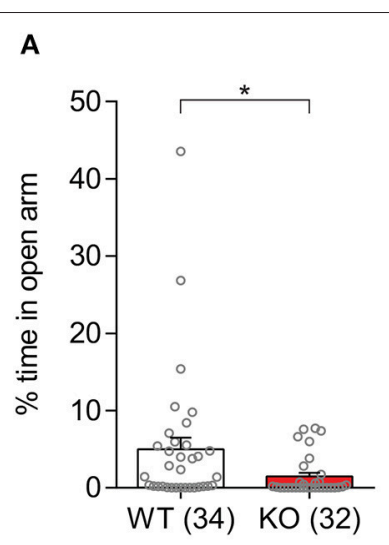

B

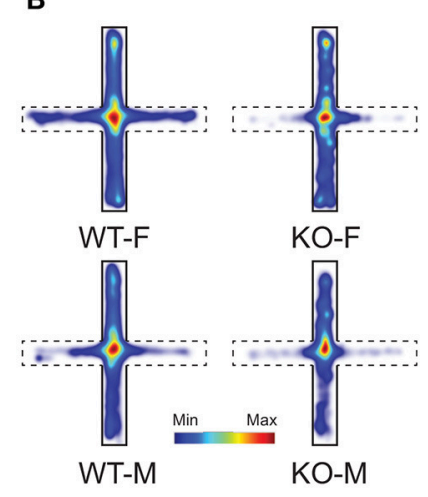

C

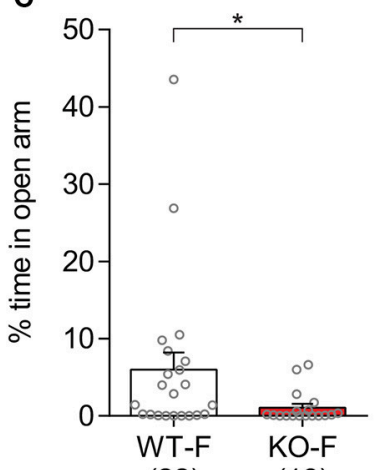

(22)
D

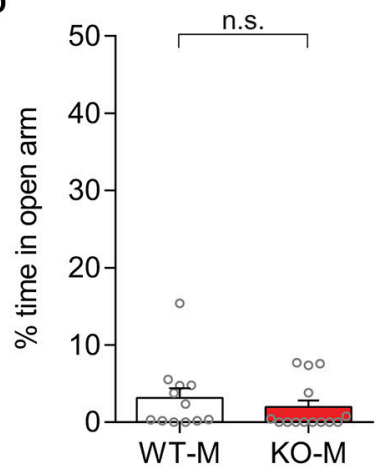

(12)

background were bred to obtain $\mathrm{Slit}^{+/+}$(WT), Slit3 ${ }^{+/-}$(Het) and Slit3 ${ }^{-1-}$ (KO). Two- to four-month old male and female WT and Slit3-KO mice were used for behavioral tests. Age and sex matched C57BL/6 were used as social partners in three-chamber social tests. All mice were housed 2-5 per cage in ventilated racks in a temperature- and humidity-controlled animal room on a $12 \mathrm{~h}$ light/dark cycle with lights on from 07:00 to 19:00 and cared by the AAALAC accredited program of the University of Maryland School of Medicine. Autoclaved rodent chow and water were available ad libitum. This study was carried out in accordance with the recommendations of the Guide for the Care and Use of Laboratory Animals, US National Research Council. The protocol was approved by the Institutional Animal Care and Use Committees at the Hussman Institute for Autism and the University of Maryland School of Medicine.

\subsection{Behavioral Tests}

Three cohorts of mice were used for behavioral tests (Table 1). The first cohort was tested in the order of: open field test, threechamber social test, and novel object recognition test. The second cohort of mice was tested in the order of: elevated plus maze, rotarod test, and marble burying test. The third cohort of mice was tested in the order of: elevated plus maze, light/dark box, and tail suspension test. There was at least a 1-week rest period between each test. Animals were moved to the testing room at least $1 \mathrm{~h}$ prior to the test. Animals' activity during behavioral assessment was video-recorded by a NIR Monochrome GigE camera or a Logitech C920 HD Pro Webcam, with EthoVision XT software (Noldus, RRID:SCR_002798) used for further offline analysis. All experiments were conducted during the light cycle. Except the elevated plus maze test and the light/dark box test, all other tests were conducted in a room with light at around 80 lux. All arenas were cleaned with $70 \%$ ethanol between test sessions.

\subsubsection{Three-Chamber Social Test}

A slightly modified three-chamber social test was conducted as previously described (Moy et al., 2004; Mei et al., 2016; Park et al., 2016). The test animal was placed in the middle chamber of the three-chamber apparatus $(40 \times 60 \times 20 \mathrm{~cm})$, with left and right chambers closed for $30 \mathrm{~s}$, and then was allowed to explore all three chambers through small openings $(10 \times 5 \mathrm{~cm})$ with an inverted steel wire pencil cup (10 cm diameter and height) placed in each side chamber for $10 \mathrm{~min}$. At the end of the exploring session, the animal was gently guided back to the middle chamber. During the second session, one novel C57BL/6 mouse was placed under one of the cups and an object was placed under the other, and then the test mouse was allowed to explore all three chambers for $10 \mathrm{~min}$. After that, the test mouse was guided back to the middle chamber. In the third session, the object was replaced by another novel C57BL/6 mouse and then the test mouse was allowed to explore all three chambers again for $10 \mathrm{~min}$. The duration that the animals spent in each zone during each session was scored using the nose point tracking in EthoVision XT software (Noldus). The interaction zone was defined as a circle area $1 \mathrm{~cm}$ around the 

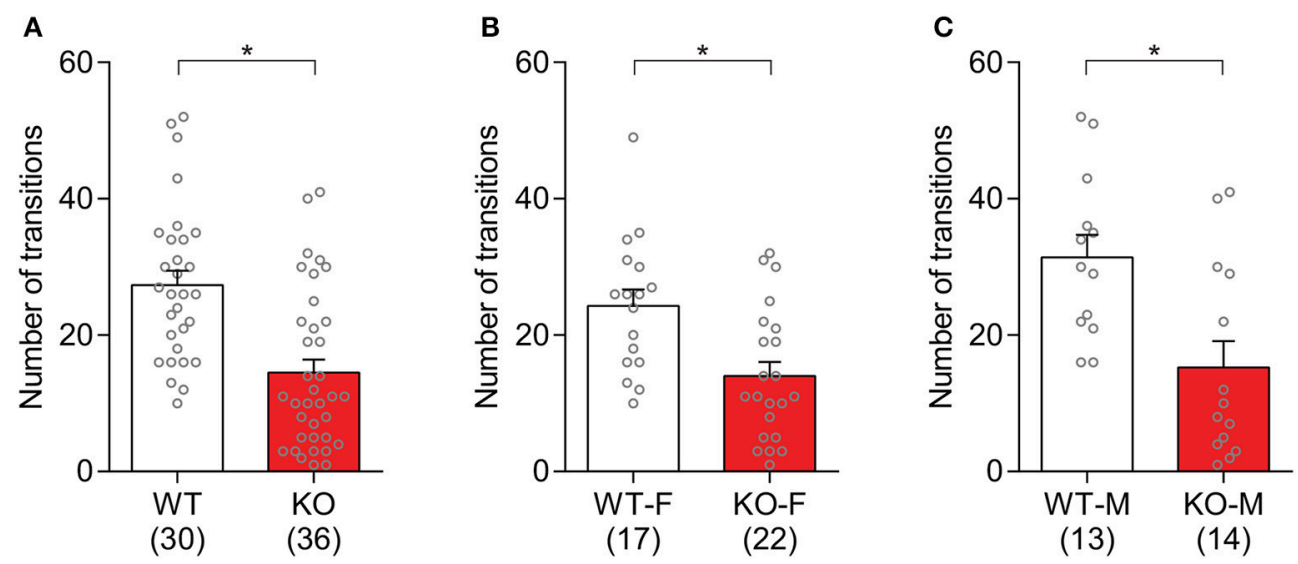

FIGURE 7 | Slit3-KO mice showed anxiety-like behaviors in the light/dark box test. (A) KO mice made fewer transitions to the light chamber during the 10-min test than WT controls. ${ }^{*} p<0.001, t$-test. (B) Number of transitions to the light compartment in female mice. ${ }^{*} p=0.002, t$-test. (C) Number of transitions to the light compartment in male mice. ${ }^{*} p=0.004$, t-test. The data in the bar chart are presented as mean \pm SEM. Sample size is indicated in parentheses. F, female; M, male.

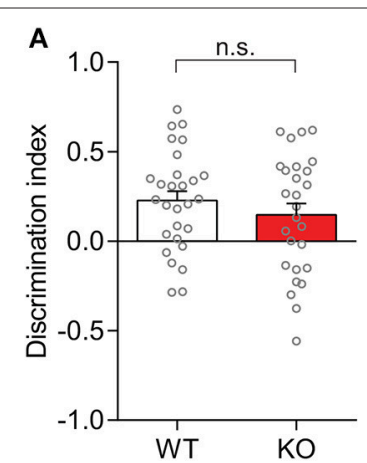

(28) (27)

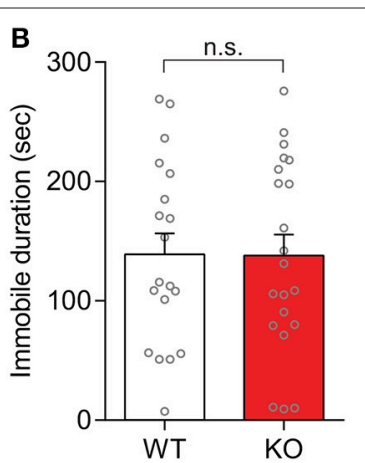

(19)

TABLE 1 | Behavioral tests and the number of animals in the three cohorts.

\begin{tabular}{|c|c|c|c|c|}
\hline Cohorts & Sex & WT & KO & Behavioral tests \\
\hline \multirow{2}{*}{$1 \mathrm{st}$} & $M$ & 16 & 18 & \multirow{2}{*}{$\begin{array}{l}\text { Open field test }{ }^{\mathrm{a}} \text {, three-chamber social test }{ }^{\mathrm{b}} \text {, } \\
\text { and novel object recognition test }{ }^{\mathrm{c}}\end{array}$} \\
\hline & $\mathrm{F}$ & 17 & 11 & \\
\hline \multirow[t]{2}{*}{ 2nd } & $M$ & 7 & 15 & \multirow{2}{*}{$\begin{array}{l}\text { Elevated plus maze }{ }^{d} \text {, rotarod test, and marble } \\
\text { burying test }{ }^{\mathrm{C}}\end{array}$} \\
\hline & $F$ & 15 & 12 & \\
\hline \multirow[t]{2}{*}{$3 r d$} & $\mathrm{M}$ & 13 & 14 & \multirow[t]{2}{*}{$\begin{array}{l}\text { Elevated plus maze }{ }^{\mathrm{e}} \text {, light/dark box, and tail } \\
\text { suspension test }{ }^{\mathrm{C}}\end{array}$} \\
\hline & $\mathrm{F}$ & 17 & 22 & \\
\hline
\end{tabular}

${ }_{1} \mathrm{KO}-\mathrm{F}$ mouse was removed as it was completely immobile during the entire test session. ${ }^{b}$ Data from 8 WT-M, 8 WT-F, $10 \mathrm{KO}-\mathrm{M}$, and $2 \mathrm{KO}-\mathrm{F}$ in the social tests were excluded due to a different strain of mice used as social partners. ' Some mice were not used for the third test in each cohort when the group size was enough for that test. ${ }^{d} 1$ WT-M, 1 KO-M, and $1 \mathrm{KO}-\mathrm{F}$ mice were excluded due to the unexpected noise disturbance or the detection difficulty because of their white fur. ${ }^{e}$ EPM tests were only scored in 7 WT-F, 6 WT-M, and $7 \mathrm{KO}-\mathrm{F}$ mice. The rest of animals were still exposed to the EPM for $10 \mathrm{~min}$ so that all animals have the same testing experience for the other two tests.

If the marble was buried more than $2 / 3$ deep, it was counted as buried.

\subsubsection{Open Field Test}

Animals were allowed to explore a novel open field apparatus $(40 \mathrm{X} 40 \mathrm{~cm}$ ) for $30 \mathrm{~min}$ to test their locomotive behaviors. In addition, exploration in the center area $(20 \times 20 \mathrm{~cm})$ during the first $10 \mathrm{~min}$ of the test was measured to examine anxietylike traits, as mice display anxiety-like behavior most often in the beginning of the open field test (first 5-10 min) (Choleris et al., 2001). Distance traveled and time spent in the center area were monitored and analyzed using EthoVision XT software (Noldus).

\subsubsection{Elevated Plus Maze Test}

The test was conducted under very dim yellow light at around 8 lux. Facing the closed arm in the elevated plus 
maze apparatus, animals were placed in the center of the elevated plus maze $(30 \times 5 \mathrm{~cm}, 15 \mathrm{~cm}$ walls on closed arms, $50 \mathrm{~cm}$ above the floor) and allowed to explore for $10 \mathrm{~min}$. The duration of time that the mice spent in each arm (animals completely entered the arm) was scored using EthoVision XT software (Noldus). The percentage of time in open arm was calculated as (duration in open arm) / (total duration).

\subsubsection{Light/Dark Box Test}

The light/dark box test apparatus consists of two parts. The brightness of the light side $(40 \times 20 \mathrm{~cm})$ was about 600 lux and the dark side $(40 \times 20 \mathrm{~cm})$ was less than 2 lux. Mice were placed in the center of the light side of the apparatus with an opening $(10 \times 5 \mathrm{~cm})$ to the dark side. Animals were allowed to explore for $10 \mathrm{~min}$. The number of transitions between chambers was scored using EthoVision XT software (Noldus), and confirmed by manual counting in random samples.

\subsubsection{Rotarod Test}

Animals' motor learning was assessed using the rotarod test (Yang et al., 2012). Animals were tested on the accelerating rotarod (Panlab, Harvard apparatus) over 2 days. Mice were habituated on the stationary rod for $60 \mathrm{~s}$ on the first day of testing. During each testing session, mice were placed on the rotating rod $(4 \mathrm{rpm})$ heading opposite to the rotating direction and received accelerating rotarod tasks (4-40 rpm over $5 \mathrm{~min}$ ). The testing sessions were repeated for three trials a day for 2 consecutive days, with a 1 -h inter-trial interval. If the animal fell off the rod within $10 \mathrm{~s}$, it was gently placed back onto the rod. If the animal turned 180 degrees on the rod, it was gently guided back to the original direction. The time delay between the test start and the animals' falling off the rod or making a complete revolution on the rod was recorded as the latency to fall.

\subsubsection{Novel Object Recognition Test}

Novel object recognition tests were performed as described previously (Cohen and Stackman, 2015). Mice were habituated in the open field box $(40 \times 40 \mathrm{~cm})$ for $10 \mathrm{~min}$ on 3 consecutive days. On the testing day, the mice were allowed to explore two identical objects located in each corner $5 \mathrm{~cm}$ from the wall for $10 \mathrm{~min}$. The mice were then placed in an empty cage. After $10 \mathrm{~min}$, the mice were placed back in the box where one of the original objects had been replaced by a novel object and the mice were allowed to explore for $5 \mathrm{~min}$. The duration of time the animals spent in the $2 \mathrm{~cm}$ space around the object was scored using EthoVision XT software (Noldus). Discrimination index was calculated as:

$$
\frac{\mathrm{D}_{\text {novel }}-\mathrm{D}_{\text {familiar }}}{\mathrm{D}_{\text {novel }}+\mathrm{D}_{\text {familiar }}}
$$

\section{REFERENCES}

Abu-Dahab, S. M. N., Skidmore, E. R., Holm, M. B., Rogers, J. C., and Minshew, N. J. (2013). Motor and tactile-perceptual skill differences between individuals where $\mathrm{D}_{\text {novel }}$ and $\mathrm{D}_{\text {familiar }}$ are the duration exploring the novel object and the duration exploring the familiar object, respectively.

\subsubsection{Tail Suspension Test}

Depression-like behaviors were tested using the tail suspension test as described previously (Steru et al., 1985; de Rezende et al., 2014). Mice were hung by the tip of the tail taped to the metal rod for $6 \mathrm{~min}$. Immobility time was measured manually.

\subsection{Statistical Analysis}

All data were analyzed with Graphpad Prism 6 software (Graphpad Prism, RRID:SCR_002798). All data sets were tested for normality using the D'Agostino-Pearson omnibus normality test. Two-tailed unpaired t-tests, paired t-test, or two-way ANOVA with repeated measures in one factor (rmANOVA) were used for the data with normal distribution. MannWhitney analysis was used when the data were not normally distributed. A value of $p<0.05$ was considered statistically significant.

\section{DATA AVAILABILITY STATEMENT}

The raw data supporting the conclusions of this manuscript will be made available by the authors to any qualified researcher upon reasonable request.

\section{AUTHOR CONTRIBUTIONS}

$\mathrm{CP}$ and SH initiated the project. CP provided the mice. SP collected and analyzed the behavioral assessment data. SP and SH designed the experiment and wrote the manuscript with the help of CP.

\section{FUNDING}

This work is supported by Hussman Foundation grants HIAS15002 and HIAS18001 to SH, and HIAS15005 to CP.

\section{ACKNOWLEDGMENTS}

We thank Dr. Gene Blatt, Dr. John Hussman, and Ms. Elizabeth Benevides for critical reading of the manuscript. We thank Dr. David Ornitz, Dr. Marc Tessier-Lavigne and Dr. Olav Olsen for their help with the Slit3 mouse line. We thank Shoshana Howarth, Karlie Menzel, and Djeneba Sidibe for their technical help with animal breeding and genotyping. We thank Drs. Louis DeTolla and Turhan Coksaygan at the University of Maryland School of Medicine for providing veterinary and consulting services.

with high-functioning autism and typically developing individuals ages 5-21. J. Autism Dev. Disord. 43, 2241-2248. doi: 10.1007/s10803-011-1439-y

An, X.-L., Zou, J.-X., Wu, R.-Y., Yang, Y., Tai, F.-D., Zeng, S.-Y., et al. (2011). Strain and Sex Differences in Anxiety-Like and Social Behaviors in 
C57BL/6J and BALB/cJ Mice. Exp. Anim. 60, 111-123. doi: 10.1538/expanim. 60.111

Andrews, W. D., Barber, M., and Parnavelas, J. G. (2007). Slit-Robo interactions during cortical development. J. Anat. 211, 188-198. doi: 10.1111/j.1469-7580.2007.00750.x

Anitha, A., Nakamura, K., Yamada, K., Suda, S., Thanseem, I., Tsujii, M., et al. (2008). Genetic analyses of roundabout (ROBO) axon guidance receptors in autism. Am. J. Med. Genet. B Neuropsychiatr. Genet. 147B, 1019-1027. doi: 10.1002/ajmg.b.30697

Bækvad-Hansen, M., Tümer, Z., Delicado, A., Erdogan, F., Tommerup, N., and Larsen, L. A. (2006). Delineation of a $2.2 \mathrm{Mb}$ microdeletion at $5 \mathrm{q} 35$ associated with microcephaly and congenital heart disease. Am. Journal of Med. Genet. 140, 27-33. doi: 10.1002/ajmg.a.31087

Bagri, A., Marín, O., Plump, A. S., Mak, J., Pleasure, S. J., Rubenstein, J. L., et al. (2002). Slit proteins prevent midline crossing and determine the dorsoventral position of major axonal pathways in the mammalian forebrain. Neuron 33, 233-248. doi: 10.1016/S0896-6273(02)00561-5

Bakos, J., Bacova, Z., Grant, S. G., Castejon, A. M., and Ostatnikova, D. (2015). Are molecules involved in neuritogenesis and axon guidance related to autism pathogenesis? Neuromol. Med. 17, 297-304. doi: 10.1007/s12017-015-8357-7

Blockus, H. and Chédotal, A. (2014). The multifaceted roles of Slits and Robos in cortical circuits: from proliferation to axon guidance and neurological diseases. Curr. Opin. Neurobiol. 27, 82-88. doi: 10.1016/j.conb.2014.03.003

Borrell, V., Cárdenas, A., Ciceri, G., Galcerán, J., Flames, N., Pla, R., et al. (2012). Slit/robo signaling modulates the proliferation of central nervous system progenitors. Neuron 76, 338-352. doi: 10.1016/j.neuron.2012.08.003

Brose, K., Bland, K. S., Wang, K. H., Arnott, D., Henzel, W., Goodman, C. S., et al. (1999). Slit proteins bind robe receptors and have an evolutionarily conserved role in repulsive axon guidance. Cell 96, 795-806. doi: 10.1016/S0092-8674(00)80590-5

Calhoon, G. G., and Tye, K. M. (2015). Resolving the neural circuits of anxiety. Nat. Neurosci. 18, 1394-1404.

Carroll, L. S., and Owen, M. J. (2009). Genetic overlap between autism, schizophrenia and bipolar disorder. 1:102. doi: 10.1186/gm102

Choleris, E., Thomas, A., Kavaliers, M., and Prato, F. (2001). A detailed ethological analysis of the mouse open field test: effects of diazepam, chlordiazepoxide and an extremely low frequency pulsed magnetic field. Neurosci. Biobehav. Rev. 25, 235-260. doi: 10.1016/S0149-7634(01)00011-2

Cohen, S. J., and Stackman, R. W. (2015). Assessing rodent hippocampal involvement in the novel object recognition task. A review. Behav. Brain Res. 285, 105-117. doi: 10.1016/j.bbr.2014.08.002

Cukier, H. N., Dueker, N. D., Slifer, S. H., Lee, J. M., Whitehead, P. L., Lalanne, E., et al. (2014). Exome sequencing of extended families with autism reveals genes shared across neurodevelopmental and neuropsychiatric disorders. Mol. Autism 5:1. doi: 10.1186/2040-2392-5-1

de Rezende, V. B., Rosa, D. V., Comim, C. M., Magno, L. A. V., Rodrigues, A. L. S., Vidigal, P., et al. (2014). NCS-1 deficiency causes anxiety and depressivelike behavior with impaired non-aversive memory in mice. Physiol. Behav. 130, 91-98. doi: 10.1016/j.physbeh.2014.03.005

Deacon, R. M. (2006). Digging and marble burying in mice: Simple methods for in vivo identification of biological impacts. Nat. Protoc. 1, 122-124. doi: $10.1038 /$ nprot.2006.20

Di Martino, A., Yan, C. G., Li, Q., Denio, E., Castellanos, F. X., Alaerts, K., et al. (2014). The autism brain imaging data exchange: towards a large-scale evaluation of the intrinsic brain architecture in autism. Mol. Psychiatry 19, 659-667. doi: 10.1038/mp.2013.78

Fanselow, M. S., and Dong, H.-W. (2010). Are the dorsal and ventral hippocampus functionally distinct structures? Neuron 65, 7-19. doi: 10.1016/j.neuron.2009.11.031

Freitag, C. M., Luders, E., Hulst, H. E., Narr, K. L., Thompson, P. M., Toga, A. W., et al. (2009). Total brain volume and corpus callosum size in medication-naïve adolescents and young adults with autism spectrum disorder. Biol. Psychiatry 66, 316-319. doi: 10.1016/j.biopsych.2009.03.011

Glessner, J. T., Wang, K., Sleiman, P. M., Zhang, H., Kim, C. E., Flory, J. H., et al. (2010). Duplication of the SLIT3 locus on $5 \mathrm{q} 35.1$ predisposes to major depressive disorder. PLoS ONE 5:e15463. doi: 10.1371/journal.pone.00 15463
Greaves, E., Collins, F., Esnal-Zufiaurre, A., Giakoumelou, S., Horne, A. W., and Saunders, P. T. (2014). Estrogen receptor (ER) agonists differentially regulate neuroangiogenesis in peritoneal endometriosis via the repellent factor SLIT3. Endocrinology 155, 4015-4026. doi: 10.1210/en.2014-1086

Griebel, G., Belzung, C., Perrault, G., and Sanger, D. J. (2000). Differences in anxiety-related behaviors and in sensitivity to diazepam in inbred and outbred strains of mice. Psychopharmacology 148, 164-170. doi: 10.1007/s0021300 50038

Hardan, A. Y., Pabalan, M., Gupta, N., Bansal, R., Melhem, N. M., Fedorov, S., et al. (2009). Corpus callosum volume in children with autism. Psychiatry Res. Neuroimaging 174, 57-61. doi: 10.1016/j.pscychresns.2009.03.005

Hou, H., Uuskula-Reimand, L., Makarem, M., Corre, C., Saleh, S., Metcalf, A., et al. (2017). Gene expression profiling of puberty-associated genes reveals abundant tissue and sex-specific changes across postnatal development. Hum. Mol. Genet. 26, 3585-3599. doi: 10.1093/hmg/ddx246

$\mathrm{Hu}$, H. (1999). Chemorepulsion of neuronal migration by Slit2 in the developing mammalian forebrain. Neuron 23, 703-711. doi: 10.1016/S0896-6273(01)80029-5

Hu, V. W., Frank, B. C., Heine, S., Lee, N. H., and Quackenbush, J. (2006). Gene expression profiling of lymphoblastoid cell lines from monozygotic twins discordant in severity of autism reveals differential regulation of neurologically relevant genes. BMC Genomics 7:118. doi: 10.1186/1471-2164-7-118

Jeste, S. S. (2011). The neurology of autism spectrum disorders. Curr. Opin. Neurol. 24, 132-139. doi: 10.1097/WCO.0b013e3283446450

Kerns, C. M., Kendall, P. C., Berry, L., Souders, M. C., Franklin, M. E., Schultz, R. T., et al. (2014). Traditional and atypical presentations of anxiety in youth with autism spectrum disorder. J. Autism Dev. Disord. 44, 2851-2861. doi: 10.1007/s10803-014-2141-7

Khanzada, N. S., Butler, M. G., and Manzardo, A. M. (2017). Geneanalytics pathway analysis and genetic overlap among autism spectrum disorder, bipolar disorder and schizophrenia. Int. J. Mol. Sci. 18:E527. doi: 10.3390/ijms180 30527

Kouser, M., Speed, H. E., Dewey, C. M., Reimers, J. M., Widman, A. J., Gupta, N., et al. (2013). Loss of predominant Shank3 isoforms results in hippocampusdependent impairments in behavior and synaptic transmission. J. Neurosci. 33, 18448-18468. doi: 10.1523/JNEUROSCI.3017-13.2013

Krupp, D. R., Barnard, R. A., Duffourd, Y., Evans, S. A., Mulqueen, R. M., Bernier, R., et al. (2017). Exonic mosaic mutations contribute risk for autism spectrum disorder. Am. J. Hum. Genet. 101, 369-390. doi: 10.1016/j.ajhg.2017.07.016

Lin, L., Lesnick, T. G., Maraganore, D. M., and Isacson, O. (2009). Axon guidance and synaptic maintenance: preclinical markers for neurodegenerative disease and therapeutics. Trends Neurosci. 32, 142-149. doi: 10.1016/j.tins.2008.11.006

Long, H., Sabatier, C., Ma, L., Plump, A., Yuan, W., Ornitz, D. M., et al. (2004). Conserved roles for Slit and Robo proteins in midline commissural axon guidance. Neuron 42, 213-223. doi: 10.1016/S0896-6273(04)00179-5

Lopez-Bendito, G., Flames, N., Ma, L., Fouquet, C., Di Meglio, T., Chedotal, A., et al. (2007). Robo1 and Robo2 cooperate to control the guidance of major axonal tracts in the mammalian forebrain. J. Neurosci. 27, 3395-3407. doi: 10.1523/JNEUROSCI.4605-06.2007

Lynch, C. J., Uddin, L. Q., Supekar, K., Khouzam, A., Phillips, J., and Menon, V. (2013). Default mode network in childhood autism: Posteromedial cortex heterogeneity and relationship with social deficits. Biol. Psychiatry 74, 212-219. doi: 10.1016/j.biopsych.2012.12.013

Marillat, V., Chédotal, A., Cases, O., Nguyen-Ba-Charvet, K. T., Tessier-Lavigne, M., and Sotelo, C. (2002). Spatiotemporal expression patterns of slit and robo genes in the rat brain. J. Comp. Neurol. 442, 130-155. doi: 10.1002/cne. 10068

McCarthy, S. E., Gillis, J., Kramer, M., Lihm, J., Yoon, S., Berstein, Y., et al. (2014). De novo mutations in schizophrenia implicate chromatin remodeling and support a genetic overlap with autism and intellectual disability. Mol. Psychiatry 19, 652-658. doi: 10.1038/mp.2014.29

Mei, Y., Monteiro, P., Zhou, Y., Kim, J. A., Gao, X., Fu, Z., et al. (2016). Adult restoration of Shank3 expression rescues selective autistic-like phenotypes. Nature 530, 481-484. doi: 10.1038/nature16971

Menon, V. (2013). Developmental pathways to functional brain networks: emerging principles. Trends Cogn. Sci. 17, 627-640. doi: 10.1016/j.tics.2013.09.015 
Menten, B., Maas, N., Thienpont, B., Buysse, K., Vandesompele, J., Melotte, C., et al. (2006). Emerging patterns of cryptic chromosomal imbalance in patients with idiopathic mental retardation and multiple congenital anomalies: a new series of 140 patients and review of published reports. 43, 625-633. doi: 10.1136/jmg.2005.039453

Miyashita, T., Yeo, S.-Y., Hirate, Y., Segawa, H., Wada, H., Little, M. H., et al. (2004). PlexinA4 is necessary as a downstream target of Islet2 to mediate Slit signaling for promotion of sensory axon branching. Development 131, 3705-3715. doi: 10.1242/dev.01228

Mohammad-Rezazadeh, I., Frohlich, J., Loo, S. K., and Jeste, S. S. (2016). Brain connectivity in autism spectrum disorder. Curr. Opin. Neurol. 29, 137-147. doi: 10.1097/WCO.0000000000000301

Moy, S. S., Nadler, J. J., Perez, A., Barbaro, R. P., Johns, J. M., Magnuson, T. R., et al. (2004). Sociability and preference for social novelty in five inbred strains: an approach to assess autistic-like behavior in mice. Genes Brain Behav. 3, 287-302. doi: 10.1111/j.1601-1848.2004.00076.x

Nguyen-Ba-Charvet, K. T. and Chédotal, A. (2002). Role of slit proteins in the vertebrate brain. J. Physiol. Paris 96, 91-98. doi: 10.1016/S0928-4257(01)00084-5

Oblak, A. L., Rosene, D. L., Kemper, T. L., Bauman, M. L., and Blatt, G. J. (2011). Altered posterior cingulate cortical cyctoarchitecture, but normal density of neurons and interneurons in the posterior cingulate cortex and fusiform gyrus in autism. Autism Res. 4, 200-211. doi: 10.1002/aur.188

O'Reilly, C., Lewis, J. D., and Elsabbagh, M. (2017). Is functional brain connectivity atypical in autism? A systematic review of EEG and MEG studies. PLoS ONE 12:e0175870. doi: 10.1371/journal.pone.0175870

Park, S. M., Chen, M., Schmerberg, C. M., Dulman, R. S., Rodriguiz, R. M., Caron, M. G., et al. (2016). Effects of $\beta$-arrestin-biased dopamine D2 receptor ligands on schizophrenia-like behavior in hypoglutamatergic mice. Neuropsychopharmacology 41, 704-715. doi: 10.1038/npp.2015.196

Perez, C., Sawmiller, D., and Tan, J. (2016). The role of heparan sulfate deficiency in autistic phenotype: potential involvement of Slit/Robo/srGAPs-mediated dendritic spine formation. Neural Dev. 11:11. doi: 10.1186/s13064-016-0066-X

Plachez, C., Andrews, W., Liapi, A., Knoell, B., Drescher, U., Mankoo, B., et al. (2008). Robos are required for the correct targeting of retinal ganglion cell axons in the visual pathway of the brain. Mol. Cell. Neurosci. 37, 719-730. doi: 10.1016/j.mcn.2007.12.017

Plachez, C., and Richards, L. J. (2005). Mechanisms of axon guidance in the developing nervous system. Curr. Top. Dev. Biol., 69, 267-346. doi: 10.1016/S0070-2153(05)69010-2

Schafer, I. A., Robin, N. H., Posch, J. J., Clark, B. A., Izumo, S., and Schwartz, S. (2001). Distal 5q deletion syndrome: phenotypic correlations. Am. J. Med. Genet. 103, 63-68. doi: 10.1002/ajmg.1513

Schiffer, C., Popp, S., Moshir, S., Rupprath, G., Düngfelder, E., Hager, H. D., et al. (2003). Multicolor chromosomal bar coding characterizes a de novo interstitial deletion (5)(q33.3q35.2) in a child with multiple congenital malformations. Clin. Dysmorphol. 12, 129-131. doi: 10.1097/01.mcd.0000061821.13019.38

Shi, Y., Zhao, X., Yu, L., Tao, R., Tang, J., La, Y., et al. (2004). Genetic structure adds power to detect schizophrenia susceptibility at SLIT3 in the Chinese Han population. Genome Res. 14, 1345-1349. doi: 10.1101/gr.1758204

Shu, T., and Richards, L. J. (2001). Cortical axon guidance by the glial wedge during the development of the corpus callosum. J. Neurosci. 21, 2749-2758. doi: 10.1523/JNEUROSCI.21-08-02749.2001

Silverman, J. L., Yang, M., Lord, C., and Crawley, J. N. (2010). Behavioural phenotyping assays for mouse models of autism. Nat. Rev. Neurosci. 11, 490-502. doi: 10.1038/nrn2851

Steru, L., Chermat, R., Thierry, B., and Simon, P. (1985). The tail suspension test: a new method for screening antidepressants in mice. Psychopharmacology 85, 367-370. doi: 10.1007/BF00428203
Suda, S., Iwata, K., Shimmura, C., Kameno, Y., Anitha, A., Thanseem, I., et al. (2011). Decreased expression of axon-guidance receptors in the anterior cingulate cortex in autism. Mol. Autism 2:14. doi: 10.1186/2040-2392-2-14

Tamada, K., Tomonaga, S., Hatanaka, F., Nakai, N., Takao, K., Miyakawa, T., et al. (2010). Decreased exploratory activity in a mouse model of $15 \mathrm{q}$ duplication syndrome; implications for disturbance of serotonin signaling. PLoS ONE 5:e15126. doi: 10.1371/journal.pone.0015126

Tovote, P., Fadok, J. P., and Lüthi, A. (2015). Neuronal circuits for fear and anxiety. Nat. Rev. Neurosci. 16, 317-331. doi: 10.1038/nrn3945

Uddin, L. Q., Menon, V., Young, C. B., Ryali, S., Chen, T., Khouzam, A., et al. (2011). Multivariate searchlight classification of structural magnetic resonance imaging in children and adolescents with autism. Biol. Psychiatry 70, 833-841. doi: 10.1016/j.biopsych.2011.07.014

Unni, D. K., Piper, M., Moldrich, R. X., Gobius, I., Liu, S., Fothergill, T., et al. (2012). Multiple Slits regulate the development of midline glial populations and the corpus callosum. Dev. Biol. 365, 36-49. doi: 10.1016/j.ydbio.2012.02.004

van Steensel, F. J. A., Bögels, S. M., and Perrin, S. (2011). Anxiety disorders in children and adolescents with autistic spectrum disorders: a meta-analysis. Clin. Child Fam. Psychol. Rev. 14, 302-317. doi: 10.1007/s10567-011-0097-0

Võikar, V., Kõks, S., Vasar, E., and Rauvala, H. (2001). Strain and gender differences in the behavior of mouse lines commonly used in transgenic studies. Physiol. Behav. 72, 271-281. doi: 10.1016/S0031-9384(00)00405-4

Wang, K. H., Brose, K., Arnott, D., Kidd, T., Goodman, C. S., Henzel, W. et al. (1999). Biochemical purification of a mammalian slit protein as a positive regulator of sensory axon elongation and branching. Cell 96, 771-784. doi: 10.1016/S0092-8674(00)80588-7

White, S. W., Oswald, D., Ollendick, T., and Scahill, L. (2009). Anxiety in children and adolescents with autism spectrum disorders. Clin. Psychol. Rev. 29, 216 229. doi: 10.1016/j.cpr.2009.01.003

Whitford, K. L., Marillat, V., Stein, E., Goodman, C. S., Tessier-Lavigne, M., Chédotal, A., et al. (2002). Regulation of cortical dendrite development by Slit-Robo interactions. Neuron 33, 47-61. doi: 10.1016/S0896-6273(01)00566-9

Wurzman, R., Forcelli, P. A., Griffey, C. J., and Kromer, L. F. (2015). Repetitive grooming and sensorimotor abnormalities in an ephrin-A knockout model for Autism Spectrum Disorders. Behav. Brain Res. 278, 115-128. doi: 10.1016/j.bbr.2014.09.012

Yang, M., Bozdagi, O., Scattoni, M. L., Wohr, M., Roullet, F. I., Katz, A. M.,et al. (2012). Reduced excitatory neurotransmission and mild autism-relevant phenotypes in adolescent Shank3 null mutant mice. J. Neurosci. 32, 6525-6541. doi: 10.1523/JNEUROSCI.6107-11.2012

Yuan, W., Rao, Y., Babiuk, R. P., Greer, J. J., Wu, J. Y., and Ornitz, D. M. (2003). A genetic model for a central (septum transversum) congenital diaphragmatic hernia in mice lacking Slit3. Proc. Natl. Acad. Sci. U.S.A. 100, 5217-5222. doi: 10.1073/pnas.0730709100

Yuan, W., Zhou, L., Chen, J. h., Wu, J. Y., Rao, Y., and Ornitz, D. M. (1999). The mouse SLIT family: secreted ligands for ROBO expressed in patterns that suggest a role in morphogenesis and axon guidance. Dev. Biol. 212, 290-306. doi: $10.1006 /$ dbio.1999.9371

Conflict of Interest Statement: The authors declare that the research was conducted in the absence of any commercial or financial relationships that could be construed as a potential conflict of interest.

Copyright (C) 2018 Park, Plachez and Huang. This is an open-access article distributed under the terms of the Creative Commons Attribution License (CC BY). The use, distribution or reproduction in other forums is permitted, provided the original author(s) and the copyright owner(s) are credited and that the original publication in this journal is cited, in accordance with accepted academic practice. No use, distribution or reproduction is permitted which does not comply with these terms. 